\title{
Taking measures of secondary prevention of coronary heart disease in clinical practice
}

\author{
Dusko B. Vulic, MD, PhD, FESC, FACC \\ Department of Internal Medicine, University of Banja Luka , Banja Luka, Republic of Srpska, Bosnia and Herzegovina
}

Abstract Recommendations for prevention of coronary heart disease are measures that are available to both individuals and entire populations to detect diseases and faster and more successful intervention, respectively a measure directed against the progression or recurrence of diseases in people with established disease. Secondary prevention of coronary heart disease seemed to measures aimed at preventing relapses and progression of atherosclerosis in people who already have developed disease.Modification of coronary risk factors is a key part of secondary prevention of coronary bolesti.The main risk factors remain important predictors of long-term prognosis in patients with coronary artery disease. New studies on the application of measures of secondary prevention of coronary heart disease showed a high prevalence of adverse lifestyle characteristics, other risk factors and inadequate use of prophylactic drugs in patients with coronary disease. Inadequate treatment of risk factors in coronary patients is similar in Europe and other parts of the world.

Key words coronary heart disease, cardiovascular disease, risk factors, guidelines, prevention

\section{Introduction}

Cardiovascular diseases (CVDs), among which coronary heart disease is the most common, are the major cause of death in middle age and older people in most European countries. Coronary heart disease is the leading cause of death in men over 45 and women over 65 years throughout Europe, but there are enormous differences in mortality between countries and within countries over time. CVD (including coronary heart disease and stroke) accounts for $49 \%$ of all deaths in Europe and for $30 \%$ of all deaths before the age of 65 years. One of eight men and one of seventeen women die from CVD before the age of 65 years. There is up to 10 -fold difference in premature CVD mortality between Western Europe and countries in Central and Eastern Europe, with the highest mortality rates in the east. As a result of therapeutic and preventive measures to control the $\mathrm{CHD}$ epidemic, mortality has declined steadily during the last several decades with consequent gains in life expectancy; however, this decrease in mortality started to plateau in the $1990^{\prime} \mathrm{s}^{1,2}$. Secondary prevention is identifying and treating people with established disease and those at very high risk of developing cardiovascular disease, which involves the treatment and rehabilitation of patients with known cardiovascular disease to prevent future cardiovascular events, including myocardial infarction, stroke, and heart failure. The secondary prevention patient population includes those with established coronary and other atherosclerotic vascular disease, including peripheral arterial disease, atherosclerotic aortic disease and carotid artery disease ${ }^{1}$. However, one might also consider expanding this to persons with other coronary heart disease risk equivalents, such as those with a $>20 \% 10$-year calculated risk of CHD, diabetes, chronic kidney disease, or with significant subclinical coronary atherosclerosis (e.g., high levels of coronary artery calcification). Secondary prevention of coronary artery disease is effective in reducing morbidity and mortality, but deficiencies in implementation and prescription bias have been identified.

\section{Risk factor modification and secondary prevention guidelines}

Risk factor modification is the foundation of secondary prevention efforts in persons with $\mathrm{CHD}^{1,3}$. This comprehensive approach involves lifestyle modification efforts including smoking cessation, diet, and physical activity, pharmacologic therapies to ensure control of blood pressure, lipids and glucose, and the use of cardioprotective drug therapies(Table 1). Over the past decade, guideline panels, including those from the American Heart Association (AHA) and American College of Cardiology (ACC) ${ }^{1}$ as well as European pane $\left.\right|^{10,28}$, have developed a series of recommendations for therapy and clinical management of risk factors in persons with CHD. Evidence confirms that aggressive comprehensive risk factor management improves survival, reduces recurrent events and the need for interventional procedures, and improves the quality of life in these patients. 


\section{Status of risk factor control and recommended treatments}

Previous studies have shown that cardiovascular risk factors among CHD patients are poorly controlled ${ }^{5}$, with many exceeding target levels ${ }^{6}$. Previous reports ${ }^{7}$ have focused on clinical or hospitalized samples, U.S. population data from free-living U.S. adults with CHD describing the adequacy of recommended treatments and risk factor control are limited. Recent reports from the U.S. National Health and Nutrition Examination Survey have shown barely a third of those with CVD to be at a recommended LDL-C $<100 \mathrm{mg} / \mathrm{dl}$ with only a sixth at recommended levels of all lipids, and less than half at recommended levels of blood pressure. ${ }^{8,9}$

Lifestyle, risk factor, and therapeutic goals set by recommendations of Joint European Societies for coronary disease prevention in clinical practice are not realized by most patients throughout Europe ${ }^{10,11}$. Many national multicenter studies showed results similar to those in EUROASPIRE I (1995/96), EUROASPIRE II (1999/2000), and EUROASPIRE III $(2006 / 2007)^{4,12}$, EUROASPIRE IV (2011/2012). ${ }^{30.31}$. The results of EUROASPIRE I, II , III and IV surveys demonstrated a high prevalence of unhealthy lifestyles, modifiable risk factors and inadequate use of drug therapies to achieve blood pressure and lipid goals in patients with established CHD and people at high risk of developing cardiovascular disease, with wide variations in medical practice between countries. The comparison between these EUROASPIRE surveys demonstrates a substantial gap between the standards set in the CVD prevention guidelines in clinical practice. These surveys, show that lifestyle trends in patients with CHD are growing cause for concern ${ }^{12-14,30.31}$. Other surveys have also reported inadequate risk factors management and underuse of prophylactic drug therapies in patients with CHD in Spain (PREVESE I and II) in 1994 and 1998 17-18, France (PREVENIR,1998 and 1999,Usik 1998 and 2000) ${ }^{19}$, Republic of Srpska/Bosnia and Herzegovina(ROSCOPS I,II,III,IV) in $200^{21}, 2003^{21}$, $2007^{21}$ and $2011^{29}$ Croatia (TASPIC-CRO) in $1998^{20}$ and 2003, and Serbia in 2008/200923,27. In EUROASPIRE IV study yet four out of ten patients have blood pressure levels this. Just over half of all patients on one or more anti-hypertensive drug therapies are therapeutically controlled to target. Of those on lipid lowering therapy less than a third are therapeutically controlled to target. About one half of those who were smoking at the time of their coronary event are still smoking "persistent smokers". Yet half of them intend to quit in next six months.Four out of five patients are overweight and more than half are centrallz obese and third are obese. Almost half of all patients with CHD have either self reporetd diabetes or newlz detected diabetes on an OGTT. Only $41 \%$ of all coronary patients attend a cardiac rehabilitation programme.

What is abundantly clear from these European surveys is that drug therapies are simply not insufficient and they have to be combined with the professional support to make lifestyle changes and also manage their risk factors more effectively. Simply giving a drug prescription is not enough. Patients need to understand the nature of their disease and how to manage it through achieving a healthy lifestyle and adhering to cardioprotective drug therapies over the long term. Most important of all, ad- verse lifestyle trends in the general population calls to attention the urgent need for a societal strategy for CVD prevention. They illustrate how difficult it is for individual patients to change their behavior, despite the development of life-threatening disease, given that their unhealthy life-styles are shared by an ever-increasing proportion of the adult population. To help patients to quit smoking, adopt a healthy diet and increase physical activity requires sustained professional support. All patients with coronary disease as well as those at high risk of development CVD should be able to access preventive cardiology programs ${ }^{14,17,30,31}$.

Vulic et al. recently reported treatment rates for recommended treatments (ACE/ARBs, beta-blockers and lipid-lowering medication) are higher than reports from previous investigations in clinical populations that have examined CHD patients ${ }^{21}$ Adherence to lifestyle advice about diet, exercise and smoking cessation following acute coronary syndrome (ACS) has a substantial effect on lowering the risk of further events, according to a study of more than 18,000 patients ${ }^{24}$. According to an accompanying editorial, this marked improvement in cardiovascular morbidity and mortality seen with lifestyle modification in the ACS population is "a novel and compelling finding". The editorial adds that such results "should raise a new level of focus on the timely initiation of behavioral modification after MI, similar to what is currently done with acute pharmacological intervention". It was striking in the study that at 30 days following ACS, $96.1 \%$ of subjects had been prescribed antiplatelet drugs and $78.9 \%$ statins, while around one-third of smokers were still smoking, and adherence to neither diet nor exercise recommendations was reported by $28.5 \%$.

Multiple studies of the use of these recommended therapies in appropriate patients continue to show that many patients in whom therapies are indicated are not receiving them in actual clinical practice. The AHA, ACC and ESC urge that in all medical care settings where these patients are managed that programs to provide practitioners with useful reminder clues based on the guidelines, and continuously assess the success achieved in providing these therapies to the patients who can benefit from them be implemented. Data from a national samples of people with CHD show that a substantial majority were not optimally treated for BP, lipids, and $\mathrm{HbA1c}$, but better in comparison with previous reports. 22,25,30,31 Further research into identification of patient and provider factors, resulting in suboptimal treatment, is needed. Further education of patients and providers in the appropriate use of multiple or combination treatments to appropriately treat risk factors to goal is also needed, General practitioners are in a unique position to provide ongoing advice, support and counseling to such patients with established CHD, who require life-long risk factor control and treatment management.

\section{Conclusions}

Patients with established heart disease or CVD risk equivalents are at high risk for acute coronary events. Multiple randomized clinical trials have documented the valuable clinical benefits of aggressive risk factor modification for the prevention of recurrent events and mortality. 
Guidelines established by European, American, and other societies have described the assessment, goals, and management strategies for key areas of secondary prevention including smoking cessation, blood pressure control, lipid management, physical activity, weight management, diabetes management, antiplatelet therapy, renin-angiotensin system blockade, beta-blockade, and most recently, influenza vaccination. All coronary patients should be offered comprenhensive multidisciplinary preventive programme to reduce their total cardiovascular risk.

\section{References}

1. Smith SC Jr, Allen J, Blair SN, Bonow RO, Brass LM, Fonarow GC, Grundy SM, Hiratzka L, Jones D, Krumholz HM, Mosca L, Pasternak RC, Pearson T, Pfeffer MA, Taubert KA; AHA/ACC; National Heart, Lung, and Blood Institute. AHA/ACC Guidelines for Secondary Prevention Patients with Coronary and other Atherosclerotic Vascular Disease: 2006 update. Circulation 2006;113:2363-2372.

2. Smith SC Jr, Bonow RO, Creager MA, Gibbons R al: INational Heart, Lung, and Blood Institute. AHA/ACC Guidelines for Secondary Prevention Patients with Coronary and other Atherosclerotic Vascular Disease: 2011 update. Circulation 2011;124:00-00.

3. Califf RM, Armstrong PW, Carver JR, D'Agostino RB, Strauss WE. $27^{\text {th }}$ Bethesda Conference: matching the intensity of risk factor management with the hazard for coronary disease events. Task Force 5. Stratification of patients into high, medium, and low risk subgroups for purposes of risk factor management. J Am Coll Cardiol 1996;27:1007-19.

4. Davigius ML, Lioyd-Jones DM, Pirzada A. Preventing cardiovascular disease in the $21^{\text {st }}$ century: Therapeutic and preventive implications of current evidence. Am J Cardiovasc Drugs 2006;6(2):87-101.

5. EUROSPIRE I and II Group. Clinical reality of coronary prevention guidelines: a comparation of EUROSPIRE I and II in nine countries. Lancet 2001;357:995-1001.

6. Wong ND, Cupples LA, Ostfeld AM, Levy D, Kannel WB. Risk factors for long-term coronary prognosis following initial myocardial infarction: the Framingham Study. Am J Epidemiol 1989; 130: 469-80.

7. LaBresh KA, Fonarow GC, Smith SC Jr, et al. Get with the guidelines Steering Committee. Improved treatment of hospitalized coronary artery disease patients with the get with the guidelines program. Crit Pathw Cardiol 2007; 6: 98-105.

8. Fonorow GC, French WJ, Parsons LS, Sun H, Malmgren JA. Use of lipid-lowering medications at discharge in patients with acute myocardial infarction: Data from the National Registry of Myocardial Infarction 3. Circulation 2001;103:38-44.

9. Ghandehari H, Kamal-Bahl S, Wong ND. Prevalence and extent of dyslipidemia and recommended lipid levels in US adults with and without cardiovascular comorbidities: the National Health and Nutrition Examination Survey 2003-2004. Am Heart J 2008; 156: 112-9.

10. Graham I, Atar D, Borch-Johnsen K, et al. European Guidelines on Cardiovascular Disease Prevention in clinical practice: full text. Fourth Joint Task Force of the European Society of Cardiology and other Societies on Cardiovascular Disease prevention in clinical practice. Eur J Cardiovasc Prev Rehabil 2007; 14(Supp2):S1-S113.

11. Kotseva K, Wood D, De Backer G, et al. EUROASPIRE III: A survey on the lifestyle, risk factors and use of cardioprotective drug therapies in coronary patients from twenty-two European countries. Eur J Cardiovasc Prev Rehabil 2009; 16:121-137.

12. Kotseva K, Wood D, De Backer G, et al. Cardiovascular prevention guidelines in daily practice: a comparison of EUROASPIRE I, II, III surveys in eight European countries. Lancet 2009; 373: 929-940.
13. Brekke M, Gjelsvik B. Secondary cardiovascular risk prevention we can do better. Lancet 2009; 373:873-974.

14. Brook RD, Greenland P. Secondary prevention. In: Wong ND, Black HR, Gardin JM, ed. Textbook of Preventive Cardiology: A Practical Approach. McGraw-Hill Companies; 2005:583-599.

15. Fonarow GC. Implementation of preventive cardiology guidelines. In: Wong ND, Black HR, Gardin JM, ed. Textbook of Preventive Cardiology: A Practical Approach. McGraw-Hill Companies;2005:583-599.

16. Wood AD, Kotseva K. Should cardiovascular disease prevention be undertaken by doctors or policymakers and politicians? Dialogues in Cardiovasc Med 2009;14:83-98.

17. De Velasco JA, Cosin J, Lopez-Sendon JL, et al. Secondary prevention of myocardial infarction in Spain. The PREVESE study. Rev Esp Cardiol.1997;50:406-415.

18. De Velasco JA, Cosin J, Lopez-Sendon JL, De Teresa E, De Oya M, Sellers G. New data on secondary prevention of myocardial infarction in Spain. Results of PREVESE II study. Rev Esp Cardiol 2002; 55: 801-809.

19. Danchin N, Hanania G, Grenter O, et al. Trends in discharge prescriptions for patients hospitalized for acute coronary syndrome in France from 1995 to 2000.Data from the Usik 1995,PREVENIR 1,2 and Usic 2000 surveys. Ann Cardiol Angeiol 2003;52:1-6.

20. Reiner Z, Mihatov S, Milicic D, Bergovec M, Planinc D. Treatment and secondary prevention of ischaemic coronary events in Croatia(TASPIC-CRO study). Eur J Cardiovasc Prev Rehabil 2006; 13:646-654.

21. Vulic D, Loncar S, Krneta M, Skrbic R, Lazarevic A, Lee TB, Lopez VA, Wong ND. Risk factors control and adherence to treatment in Republic of Srpska-Bosnia and Herzegovina in patients with coronary heart disease 2005-2006. Archives of Medical Science 2010.

22. Vulic D, Lee TB, Lopez AV, Wong DN. Extent of control of cardiovascular risk factors and compliance to recommended therapies in U.S. multiethnic adults with coronary heart disease 2005-2006. Am J Cardiovasc Drugs 2010; 10(2): 109-14.

23. Tasic I, Lazarevic G, Kostic D, Djordjevic D, Simonovic D, Rihter M, Vulic D, Stefanovic V: Adminstration and effects of Secondary Prevention measures in coronary heart disease patients from Serbia according to gender and cardiometabolic risk.Acta Cardiol 2010:65(4):407-414.

24. Chow CK, Jolly S, Rao-Melacini P. et al. Association of diet, exercise, and smoking modification with risk of early cardiovascular events after acute coronary syndromes. Circulation 2010; 121: 750-758.

25. Wong ND, Vulic D, Sobot M. Implementation of Secondary Prevention Methodologies in Ischemic Heart Disease,Scrip Med 2010;41,1:29-35.

26. Vulić D, Krneta M, Šobot M: Guidelines of secondary prevention coronary heart disease prevention, Heart and Blood Vessels,2011: 30(4),241-246.

27. Tasić I, Kostić S, Lazarević G, Simonović D, Rihter M, Mitić M, Đorđević D, Jončić B, Stefanović V, Vulić D: Implementation of measures secondary prevention at CHD patients/Republic of Srbija, Heart and blood vesels, 2011; 30(4): 234-240.

28. Perk J, Backer DG, Gohle H, et al. European Guidelines on cardiovascular disease prevention in clinical practice (version 2012), European Heart Journal (2012) 33, 1635-1701.

29. Vulić D, Djekić D, Lončar S, Krneta M, Lazarević A, Šormaz Lj. Results of follow up CHD patients. Republic of Srpska (ROSCOPS IV), Third of Congress of Cardiologist Republic of Srpska, Abstract Book, Banja Luka, 2012.

30. Kotseva K. EUROASPIRE IV European Survey of Cardiovascular Disease Prevention and Diabetes, Medical Risk Factors, ESC 2013, Amsterdam

31. Wood D. EUROASPIRE IV Conclusions and recommendations, ESC 2013, Amsterdam. 